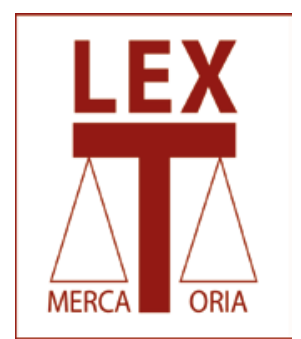

\title{
Defensa de la competencia, acción de daños y exenciones
}

Autor/a

Isabel Rodríguez Díaz

Profesora de Derecho Mercantil. Universidad de Las Palmas de Gran Canaria, Departamento de Ciencias Jurídicas Básicas.
REVISTA LEX

MERCATORIA.

Doctrina, Praxis, Jurispru-

dencia y Legislación

RLM nº6 | Año 2017

Artículo n ${ }^{0} 12$

Páginas 79-85

revistalexmercatoria.umh.es

ISSN 2445-0936
1. El nuevo artículo 75.1 de la Ley de Defensa de la Competencia

El Real Decreto-ley 9/2017, de 26 de mayo, por el que se transponen directivas de la Unión Europea en los ámbitos financiero, mercantil y sanitario, y sobre el desplazamiento de trabajadores, contiene las modificaciones derivadas de la transposición de la Directiva 2014/104/UE del Parlamento Europeo y del
Consejo, de 26 de noviembre de 2014 que establece determinadas normas por las que se rigen, en virtud del Derecho nacional, las acciones de daños resultantes de las infracciones del Derecho de la competencia de los Estados miembros y de la Unión Europea. El citado Real Decreto-ley 9/2017 modifica la Ley 15/2007, de 3 de julio, de Defensa de la Competencia (LDC), introduciendo un nuevo título VI relativo a la compensación de los daños 
causados por las prácticas restrictivas de la competencia, que abarca los artículos 71 a 81.

El artículo 71 dispone que los infractores del Derecho de la competencia serán responsables de los daños y perjuicios causados, considerándose infracción del Derecho de la competencia toda infracción de los artículos 101 y 102 del Tratado de Funcionamiento de la Unión Europea así como de los artículos 1 y 2 de la LDC. Por su parte, el artículo 72 establece el derecho de cualquier persona perjudicada por una infracción del Derecho de la competencia a reclamar al infractor ante la jurisdicción civil ordinaria, así como a obtener el pleno resarcimiento, entendiéndose por tal el hecho de devolver al perjudicado a la situación en que se habría encontrado de no haberse cometido la infracción, por lo que el resarcimiento comprenderá el daño emergente, el lucro cesante y el pago de los intereses. La acción para exigir la responsabilidad por daños y perjuicios tendrá un plazo de prescripción de cinco años.

En lo que a nuestro interés se refiere, el artículo 75.1 dice así:

"La constatación de una infracción del Derecho de la competencia hecha en una resolución firme de una autoridad de la competencia española o de un órgano jurisdiccional español se considerará irrefutable a los efectos de una acción por daños ejercitada ante un órgano jurisdiccional español".

De este interesante precepto se pueden extraer, en principio, las siguientes conclusiones: 1) que los tribunales civiles que tengan que resolver sobre una acción de daños interpuesta a raíz de un ilícito antitrust, quedan vinculados por una resolución firme que daclare la existencia de una infracción del Derecho de la competencia, por lo que no podrán entrar a dilucidar nuevamente sobre si existe o no di- cha infracción, y mucho menos resolver en sentido contradictorio; 2) que los tribunales civiles únicamente quedarán vinculados ante resoluciones que declaren la existencia de una infracción y no frente a aquellas otras que constaten su inexistencia o anulen otras anteriores que sí lo habían determinado; 3) que las resoluciones vinculantes a que hace referencia el precepto son aquellas dictadas por una autoridad de defensa de la competencia y por los tribunales de lo contencioso-administrativos; y 4) que dicha resolución vinculante ha de ser firme, y lo es cuando no ha sido recurrida o, recurrida, ha sido confirmada en la vía contencioso-administrativa ${ }^{1}$.

La aplicación privada del Derecho de la competencia trae consigo que tanto la jurisdicción contencioso-administrativa como la civil estén facultadas para declarar una infracción del Derecho de la competencia en igualdad de condiciones, siendo ambas concurrentes y totalmente autónomas e independientes, sin que exista la obligación, aunque sí la posibilidad, de suspender el juicio civil en espera de un pronunciamiento de las autoridades de la competencia y, en su caso, de los tribunales de lo contencioso-administrativo, sobre la posible comisión de una infracción. El riesgo de encontrarnos ante sentencias contradictorias es real.

Una de las cuestiones que puede plantear dudas, es la de si la declaración de una infracción del Derecho de la competencia por un tribunal civil vincula a las autoridades de la competencia y a los tribunales de lo contencioso administrativo en orden a su pronunciamiento sobre la misma cuestión. Ante esto podría decirse que si uno de los fundamentos de la norma contenida en el artículo 75 de la LDC es el de evitar sentencias contradictorias que resuelvan sobre una misma conducta, seme- 
jante argumento sería igualmente válido para sostener el carácter vinculante de una resolución declarativa de una infracción del Derecho de la competencia dictada por un tribunal civil frente a una autoridad de la competencia o tribunal de lo contencioso-administrativo. No obstante, nos decantamos porque no sea así, y ello por varias razones: 1 ) la especialización en la materia de que gozan las autoridades de la competencia y los tribunales de los contencioso-administrativos frente a los tribunales civiles, especialización que los convierte en verdaderas autoridades en la aplicación de la LDC; 2) el artículo 15 bis de la Ley de Enjuiciamiento $\mathrm{Civil}^{2}$, conforme al cual la participación de las autoridades de la competencia en un juicio civil se plantea como una posibilidad y no como una obligación, no siendo vinculantes para el juez de la causa las observaciones, documentación y valoración que sobre el tema litigioso pudieran aportar aquellas; y 3) el artículo 75 de la LDC señala que la constatación de una infracción del Derecho de la competencia realizada en una resolución firme por una autoridad de la competencia u órgano jurisdiccional españoles, se considerará irrefutable a los efectos de una acción por daños, y añadimos, única y exclusivamente en este caso. Dado que quienes resuelven las acciones por daños son los tribunales civiles, es a ellos a quienes afecta la vinculación, y a quienes hace referencia el precepto sin que quepa plantear recorrido alguno en sentido contrario.

Un tema diferente por el que sí podemos preguntarnos con mayor rigor a raíz del citado precepto, es el de si un tribunal civil que decide sobre una acción de daños planteada por una infracción del Derecho de la competencia, quedaría vinculado por una resolución previa de otro tribunal civil que ya hubiese declarado dicha infracción. Lógicamente, el pronunciamiento anterior debe de haberse produ- cido en respuesta al ejercicio de otras acciones civiles diferentes (por ejemplo, acciones derivadas del cumplimiento de un contrato supuestamente abusivo) interpuestas por los mismos sujetos, o a idénticas acciones de daños ejercitadas por distintas personas físicas o jurídicas frente a la misma infracción ya verificada. En este caso, la respuesta ha de ser afirmativa, y a nuestro entender lo es porque el artículo 75 de la LDC habla de la constatación de una infracción del Derecho de la competencia hecha en resolución firme por un órgano jurisdiccional español, sin especificar si dicho órgano es de lo contencioso-administrativo o de lo civil, de ahí que pueda y deba interpretarse en este caso que el precepto hace referencia a los dos. Por el contrario, y siguiendo la literalidad del precepto, puesto que las resoluciones administrativas o judiciales de cualquier clase declarativas de una infracción del Derecho de la competencia vinculan a los tribunales civiles que resuelvan acciones de daños, y únicamente en este supuesto, las infracciones del Derecho de la competencia constatadas por un juez civil en estos casos no vinculan a otros jueces civiles que decidan sobre acciones que no sean de daños.

Por último, no son vinculantes para los tribunales civiles las decisiones de archivo de una denuncia, que pueden deberse a diversas causas, entre otras, a tratarse de un caso incardinable en las conductas de menor importancia que trataremos a continuación.

\section{Exenciones de la Ley de Defensa de la Competencia y conductas de menor importancia.}

Es característica esencial de las conductas exentas la concurrencia de los elementos descritos en el tipo infractor ${ }^{3}$. Una vez pre- 
sentes todos ellos, la LDC contempla diversas clases de exenciones que las deja a salvo de sanción administrativa alguna. Estas son: 1) la del apartado 3 del artículo 1, cuyo fundamento jurídico se encuentra en el efecto beneficioso que la conducta produce siempre que los consumidores y usuarios participen de sus ventajas, el daño causado sea el estrictamente necesario para alcanzar el beneficio obtenido y se mantenga la libre competencia, de ahí que sea calificable como conducta ajustada a Derecho; y 2) igualmente se ajustan a Derecho las conductas amparadas por las exenciones reglamentarias de los apartados 4 y 5 del artículo 1, y por las exenciones legales dispuestas por el artículo $4^{4}$.

Las exenciones expuestas vinculan a los tribunales civiles en su interpretación y aplicación del Derecho de la competencia, pues se trata de exenciones que emanan de una norma y, por ello, incuestionables. No sucede lo mismo cuando, en aplicación de dichas exenciones, una resolución administrativa o sentencia de la jurisdicción contencioso administrativa, declara que una conducta no infringe el Derecho de la competencia al concurrir una exención de las allí previstas, ajustándose pues el comportamiento a Derecho. Estas opiniones sí son cuestionables. En estos casos, el juez civil que resuelve sobre una acción de daños ante una infracción del Derecho de la competencia, es autónomo e independiente para valorar si la infracción y la causa de exención acontecen o no y, con ello, el derecho del perjudicado a ser indemnizado. ¿Qué pueden haber sentencias contradictorias? Ya hemos señalado que sí.

Pero, ¿qué sucede con las conductas de menor importancia?
De exención las califica el Preámbulo de la LDC al decir que "se extiende a todos los tipos de infracción previstos en este capítulo la exención de las conductas que resulten de la aplicación de una norma con rango de Ley $y$ de las conductas «de mínimis»". De esta manera, el artículo 5 de la LDC dispone que:

"Las prohibiciones recogidas en los artículos 1 a 3 de la presente Ley no se aplicarán a aquellas conductas que, por su escasa importancia, no sean capaces de afectar de manera significativa a la competencia. Reglamentariamente se determinarán los criterios para la delimitación de las conductas de menor importancia, atendiendo, entre otros, a la cuota de mercado".

El citado precepto nos suscita de entrada las siguientes reflexiones: 1) son conductas de mínimis aquellas que afectan a la competencia, aunque no de manera significativa; 2) se las califica de escasa importancia debido a su también escaso impacto en la competencia; 3) a estos comportamientos no se les aplicarán las prohibiciones recogidas en los artículos 1 a 3 de la LDC; 4) no son susceptibles de sanciones administrativas; y 5) por reglamento se determinarán los criterios para la delimitación de estas conductas.

Y así se ha hecho. El RD 261/2008, de 22 de febrero, por el que se aprueba el Reglamento de Defensa de la Competencia (RDC), dispone tres artículos donde atiende a diferentes criterios, como son la cuota de mercado, criterios objetivos y criterios económicos y jurídicos (por ejemplo, la duración de la conducta o la cifra relativa del negocio afectado por el acuerdo o una cuota de mercado muy reducida), estos últimos dejados a la libre apreciación de las autoridades administrativas. Por último, los criterios delimitativos de las 
conductas de menor importancia pueden ser desarrollados por la Comisión a través de comunicaciones ${ }^{5}$.

Pero, ¿son las conductas de menor importancia comportamientos lícitos o ilícitos?

La pregunta se plantea a raíz de una discusión doctrinal entre quienes sostienen que, tal y como señala el artículo 5, la infracción del Derecho de la competencia existe, lo que permite calificar de antijurídicas las conductas de menor importancia. Al partir el precepto de una vulneración real o potencial de la libre competencia, el comportamiento puede causar o llegar a causar perjuicios a terceros. De esta manera, la actuación en cuestión, aunque no perseguible por instancias públicas, no impide el ejercicio de una acción de daños en cualquier caso $^{6}$.

Frente a esta postura, están los que señalan que la regla de mínimis es un supuesto de actuación conforme a Derecho ${ }^{7}$. Ello se debe a que el propio artículo 5 dispone que no se les aplicarán las prohibiciones de los artículos 1 a 3, de ahí que la conducta deba reputarse lícita.

En nuestra opinión, no solo esta afirmación permite manifestar que los comportamientos de menor importancia se ajustan a Derecho, sino el mismo hecho de que, a modo de ejemplo, si observamos el artículo 4, relativo a las conductas exentas por ley, señala que "...las prohibiciones del presente capítulo no se aplicarán a las conductas que resulten de la aplicación de una ley". Cuando el precepto habla de "conductas", lógicamente se refiere a conductas anticompetitivas, señalando que no están prohibidas a pesar de ello porque así lo dispone una ley. Podríamos hacer lo mismo con el resto de las exenciones, pues, como hemos señalado, para que una exención ope- re, es preciso que exista una infracción del Derecho de la competencia. Partiendo de esta base, las conductas de mínimis son infracciones del Derecho de la competencia permitidas, amparadas por una ley. ¿Por qué se permiten? Cada exención tiene su propia razón de ser, pero en este caso se debe a su escasa importancia y afectación de la libre competencia. En unos supuestos es una norma específica la que declara que un comportamiento anticompetitivo está exento, como es el caso de las exenciones establecidas por leyes y reglamentos de los artículos 4 y 1.4 .5 de la LDC. En otros, es la propia LDC la que las dispone, como sucede con el artículo 1.3 y con la regla de mínimis del artículo 5 que ahora tratamos.

Esto significa que cuando un tribunal civil, ante una acción de daños, entra a valorar la posible existencia de una infracción del Derecho de la competencia, y el supuesto infractor alega que su conducta está amparada por la regla de mínimis, el juez deba aplicar e interpretar la LDC y su Reglamento para determinar si la exención manifestada concurre o no. Si en efecto se comprueba y califica el comportamiento como de menor importancia, no existe tal infracción del Derecho de la competencia y por tanto la conducta es ajustada a Derecho, no habiendo lugar a la reclamación de posibles daños.

No obstante lo anterior, una cuestión diferente se plantea cuando, en aplicación del artículo 53.1 de la LDC, la Comisión resuelve un expediente sancionador declarando la existencia de una conducta que, por su escasa importancia, no es capaz de afectar de manera significativa a la competencia. En este caso, y en virtud del artículo 75.1 de la LDC, la citada resolución no vincula al juez civil que resuelva sobre una acción de daños, pues, recordamos, solo lo hacen aquellas resoluciones que cons- 
tatan una infracción del Derecho de la competencia, quedando autorizado el juez de esta manera, para valorar la situación y discrepar de la opinión de la Comisión, declarando, si así fuera, la comisión de una infracción del Derecho de la competencia y el correspondiente deber de indemnizar los daños y perjuicios causados.

\section{Las declaraciones de inaplicabili- dad.}

Las contempla el artículo 6 de la LDC en los siguientes términos:

"Cuando así lo requiera el interés público, la Comisión Nacional de la Competencia, mediante decisión adoptada de oficio, podrá declarar, previo informe del Consejo de Defensa de la Competencia, que el artículo 1 no es aplicable a un acuerdo, decisión o práctica, bien porque no se reúnan las condiciones del apartado 1 o bien porque se reúnan las condiciones del apartado 3 de dicho artículo. Dicha declaración de inaplicabilidad podrá realizarse también con respecto al artículo 2 de esta Ley".

Esta previsión legal no parece contener propiamente una exención, y su existencia se debe a la necesidad de garantizar la seguridad jurídica después de que el legislador cambiara el sistema de autorización previa por el de autoevaluación. Por eso, en casos de duda y de manera excepcional, pues es necesario que así lo requiera el interés público, la Comisión, de oficio, puede declarar que una conducta no constituye una infracción del Derecho de la competencia, bien porque no reúne las condi- ciones del artículo 1.1 de la LDC, bien porque, reuniéndolas, se trata de un comportamiento incardinable en la exención prevista en el apartado 3 del mismo precepto. La misma facultad puede utilizarse en relación con el artículo 2 de la LDC, aunque en este caso únicamente para señalar que una conducta no reúne las condiciones necesarias para ser calificada de abuso de posición de dominio ${ }^{8}$.

En todos estos casos, por atipicidad o concurrencia de una causa de exención, las conductas no están prohibidas y se ajustan a Derecho. La intervención de la Comisión se justifica pues por la presencia de prácticas novedosas o carentes de precedentes administrativos y jurisprudenciales, pero también es posible que estos pronunciamientos se utilicen para otros fines, como por ejemplo, manifestar su desacuerdo ante determinadas sentencias por la forma en que han calificado alguna conducta, unificar criterios ante sentencias divergentes, o cambiar los sostenidos anteriormente ante una nueva valoración de los efectos de ciertos comportamientos sobre la competencia $^{9}$.

Los efectos de estas decisiones son meramente declarativos, por lo que no vinculan al juez civil que conozca sobre una acción de daños basada en un posible ilícito antitrust. El juez civil está facultado para sostener una opinión divergente a la de la Comisión constatando, si así lo considera, la convergencia de los requisitos que permiten calificar una conducta como colusoria o de abuso de posición de dominio, o considerando que no confluyen las notas exigidas en el artículo 1.3 de la LDC para reputar el acto en cuestión como exento. 


\section{NOTAS}

${ }^{1}$ Ver sobre las cuestiones que tratamos el trabajo de Huergo Lora, A: "La CNMC, los tribunales civiles y los contenciosoadministrativos en la aplicación del Derecho de la competencia", almacendederecho.org, http://almacendederecho.org/lacnmc-los-tribunales-civiles-y-los-contencioso-administrativos-en-la-aplicacion-del-derecho-de-la-competencial, 18 de enero de 2016.

${ }^{2}$ El artículo 15 bis.1 de la Ley 1/2000, de 7 de enero, de Enjuiciamiento Civil dispone que "La Comisión Europea, la Comisión Nacional de la Competencia y los órganos competentes de las Comunidades Autónomas en el ámbito de sus competencias podrán intervenir, sin tener la condición de parte, por propia iniciativa o a instancia del órgano judicial, mediante la aportación de información o presentación de observaciones escritas sobre cuestiones relativas a la aplicación de los artículos 81 y 82 del Tratado de la Comunidad Europea o los artículos 1 y 2 de la Ley de Defensa de la Competencia. Con la venia del correspondiente órgano judicial, podrán presentar también observaciones verbales. A estos efectos, podrán solicitar al órgano jurisdiccional competente que les remita o haga remitir todos los documentos necesarios para realizar una valoración del asunto de que se trate".

${ }^{3}$ Sobre las exenciones y las conductas de menor importancia, ver el trabajo de MONTERO ELENA, C. M.: "La regla de mínimis. Significación jurídica", Comunicaciones en propiedad industrial y derecho de la competencia, núm. 52, 2008, pgs. 93, 98, donde manifiesta que, de no concurrir todos los elementos descritos en el tipo infractor, estaríamos ante conductas atípicas y no ante conductas exentas.

${ }^{4}$ MONTERO ELENA, C. M., cit, pgs. 93, 98, afirma que esta previsión no constituye propiamente una exención, pues se trata de conductas amparadas por una norma del mismo rango que la que establece la infracción. Son excepciones al tipo infractor, y conductas jurídicas al encontrase amparadas por una ley. Por ello, quienes las realicen, actúan con arreglo a Derecho; en la misma línea, MARCOS, F.: "Artículo 4. Conductas exentas por ley", en Comentario a la Ley de Defensa de la Competencia, dirigido por José Massaguer, Jaime Folguera, José Manuel Sala y Alfonso Gutiérrez, Navarra, 2012, pgs. 243, 253, señala que el artículo 4 contiene una cláusula de excepción y justificación para ciertas restricciones de la competencia que, en principio, estarían prohibidas, pero que no pueden ser perseguidas y sancionadas al gozar de amparo legal.

${ }^{5}$ Señala PALAU RAMIREZ, F.: "Artículo 5. Conductas de menor importancia", en Comentario a la Ley de Defensa de la Competencia, cit., pgs, 313, 333, que la practica administrativa en aplicación de la actual LDC ha confirmado la relevancia de estos criterios, prevaleciendo en última instancia el análisis de los efectos de las conductas sobre la competencia, de manera que la existencia de una conducta restrictiva por el objeto constituye una presunción de ilicitud, lo que no impide su calificación como de menor importancia si se comprueba que no tiene efectos restrictivos sobre el mercado.

${ }^{6}$ Sobre la mentada discusión, ver por todos a MONTERO ELENA, C. M., cit, pgs. 93, 99 y ss, donde la autora se suma a aquellos que piensan que la conducta es antijurídica.

${ }^{7}$ MIRANDA SERRANO, L. M.: "La regla de mínimis en la Ley 15/2007, de Defensa de la Competencia, y su Reglamento de desarrollo" (1), Derecho de los Negocios, núm. 216, 2008, pgs. 5, 13-14; PALAU RAMIREZ, F.: "Artículo 5. Conductas de menor importancia", cit., pgs, 313, 321-322.

${ }^{8}$ Ver PALAU RAMIREZ, F.: "Articulo 6. Declaraciones de inaplicabilidad", en Comentario a la Ley de Defensa de la Competencia, cit., pgs. 336, 339-340, donde manifiesta que debe rechazarse otro interés publico que no sea la promoción de la seguridad jurídica en la aplicación de las prohibiciones de conductas colusorias y abusivas, y que, debido a su carácter excepcional, únicamente podrán dictarse decisiones de esta naturaleza cuando así lo exija el adecuado funcionamiento de la competencia en el mercado, como en los casos en que una conducta sea novedosa o su control de licitud carezca de precedentes.

${ }^{9}$ Véase sobre estos supuestos, PALAU RAMIREZ, F.: "Articulo 6. Declaraciones de inaplicabilidad", en Comentario a la Ley de Defensa de la Competencia, cit., pg. 336, 340. 